\title{
Changing climate patterns risk the spread of Varroa destructor infestation of African honey bees in Tanzania
}

\author{
Richard A. Giliba ${ }^{{ }^{*}} \mathbb{D}$, Issa H. Mpinga ${ }^{2}$, Sood A. Ndimuligo ${ }^{3}$ and Mathew M. Mpanda ${ }^{4}$
}

\begin{abstract}
Background: Climate change creates opportune conditions that favour the spread of pests and diseases outside their known active range. Modelling climate change scenarios is oftentimes useful tool to assess the climate analogues to unveil the potential risk of spreading suitability conditions for pests and diseases and hence allows development of appropriate responses to address the impending challenge. In the current study, we modelled the impact of climate change on the distribution of Varroa destructor, a parasitic mite that attacks all life forms of honey bees and remains a significant threat to their survival and productivity of bee products in Tanzania and elsewhere.

Methods: The data about the presence of $V$. destructor were collected in eight regions of Tanzania selected in consideration of several factors including potentials for beekeeping activities, elevation (highlands vs. lowlands) and differences in climatic conditions. A total of 19 bioclimatic datasets covering the entire country were used for developing climate scenarios of mid-century 2055 and late-century 2085 for both rcp4.5 and rcp8.5. We thereafter modelled the current and future risk distribution of $V$. destructor using MaxEnt.
\end{abstract}

Results: The results indicated a model performance of $A \cup C=0.85$, with mean diurnal range in temperature (Bio2, 43.9\%), mean temperature (Bio1, 20.6\%) and mean annual rainfall (Bio12, 11.7\%) as the important variables. Future risk projections indicated mixed responses of the potential risk of spreads of $\mathrm{V}$. destructor, exhibiting both decrease and increases in the mid-century 2055 and late-century 2085 on different sites. Overall, there is a general decline of highly suitable areas of $V$. destructor in mid- and late-century across all scenarios (rcp4.5 and rcp8.5). The moderately suitable areas indicated a mixed response in mid-century with decline (under rcp4.5) and increase (under rcp8.5) and consistent increase in late century. The marginally suitable areas show a decline in mid-century and increase in late-century. Our results suggest that the climate change will continue to significantly affect the distribution and risks spread of $V$. destructor in Tanzania. The suitability range of $V$. destructor will shift where highly suitable areas will be diminishing to the advantage of the honey bees' populations, but increase of moderately suitable sites indicates an expansion to new areas. The late century projections show the increased risks due to surge in the moderate and marginal suitability which means expansion in the areas where $V$. destructor will operate.

(Continued on next page)

\footnotetext{
* Correspondence: richard.giliba@nm-aist.ac.tz

${ }^{1}$ School of Life Sciences and Bio-Engineering, The Nelson Mandela African

Institution of Science and Technology, P.O. Box 447, Arusha, Tanzania

Full list of author information is available at the end of the article
}

\section{Springer Open}

(c) The Author(s). 2020 Open Access This article is licensed under a Creative Commons Attribution 4.0 International License, which permits use, sharing, adaptation, distribution and reproduction in any medium or format, as long as you give appropriate credit to the original author(s) and the source, provide a link to the Creative Commons licence, and indicate if changes were made. The images or other third party material in this article are included in the article's Creative Commons licence, unless indicated otherwise in a credit line to the material. If material is not included in the article's Creative Commons licence and your intended use is not permitted by statutory regulation or exceeds the permitted use, you will need to obtain permission directly from the copyright holder. To view a copy of this licence, visit http://creativecommons.org/licenses/by/4.0/. 


\begin{abstract}
(Continued from previous page)
Conclusion: The current and predicted areas of habitat suitability for $V$. destructor's host provides information useful for beekeeping stakeholders in Tanzania to consider the impending risks and allow adequate interventions to address challenges facing honey bees and the beekeeping industry. We recommend further studies on understanding the severity of $V$. destructor in health and stability of the honey bees in Tanzania. This will provide a better picture on how the country will need to monitor and reduce the risks associated with the increase of $V$. destructor activities as triggered by climate change. The loss of honey bees' colonies and its subsequent impact in bees' products production and pollination effect have both ecological and economic implications that need to have prioritization by the stakeholders in the country to address the challenge of spreading $V$. destructor.
\end{abstract}

Keywords: Apis mellifera, Apiculture, Varroa destructor, Honey bee diseases

\section{Introduction}

Honey bees (Apis mellifera L.) contribute to ecosystem services through pollination of field crops and wild flowering plants. They produce honey and beeswax that are important global commodities. The global economic value of bees in terms of pollination in agricultural crops is estimated to be between US\$235 and US\$577 billion a year (UN Environment 2016), while the global honey market size stands at 7.70 billion USD (Zion Market Research 2019). There has been a growing demand for the bee products like honey due to consumer preferences towards healthy nutrition and natural alternatives to chemical artificial sweeteners in food and beverages, personal care and cosmetics and pharmaceuticals. In Tanzanian context, beekeeping sector generates annual revenue of close to 1.7 million USD through export of honey and beeswax. The sector employs about 2 million people across its value chain (URT 2018). There exist potentials for increased production and productivity of bees' products in the country. However, there are impending challenges that affect productivity of honey bees including the prevalence of parasitic mite, Varroa destructor.

$V$. destructor attacks all life forms of its host. A native to Far East and originally a parasite of Apis cerana, the mite was noted in A. mellifera around 1950 s and spread throughout the world (Rosenkranz et al. 2010). The mite is responsible for varroosis, which affects organ development of the host honey bee. It is also responsible for transmission of bee viruses such as deformed wing virus (DWV), black queen cell virus (BQCV), acute bee paralysis virus (ABPV), Kashmir bee virus (KBV), Israel acute paralysis virus (IAPV) and slow bee paralysis virus (SBPV) that adds up to spread of other diseases (Boecking and Genersch 2008). The varroosis disease is considered as the most dangerous in honey bees (Giacobino et al. 2016; Gracia et al. 2017), and its economic damage is very huge (Muli et al. 2014). Colonies of honey bees normally die within 2 to 3 years following mite infestation (Huang 2014). Efforts to contain the mite have included the use of integrated pest management approach with deployment of mechanical, chemical and cultural innovations which ranges from prevention to interventions (Rosenkranz et al. 2010).

The life cycle of $V$. destructor is dependent solely on the host, the honey bees. Its life cycle involves two separate stages: phoretic stage and reproductive stage. In the phoretic stage, mites spend on riding adult workers or drones while feeding on them and this lasts for 5 to 11 days, even longer up to 6 months until there is no brood in the colony. It is in this phoretic stage where mites change hosts and cause transmission of bee viruses (Huang 2014; Moore et al. 2014; Nazzi and Le Conte 2016). In the reproductive stage, male and female mites mate to produce a number of spermatozoa, later allowing female mite to lay eggs in the bee capped brood cell (Huang 2014). A total of five to six eggs can be laid in a capped cell depending on whether is a worker or drone pupae. Once hatched, mite egg develops to larva to protonymph, to deutonymph before becoming an adult mite (Donzé and Guerin 1994; Huang 2014). Mature female mites leave the brood when an adult bee move out of a hive and feed on him while male and immature mites stay behind in the cell (Nazzi and Le Conte 2016). The rate of population growth depends on number of female mites, ability to reproduce and availability of brood ( $\mathrm{Al}$ Ghamdi and Hoopingarner 2004).

Mites can transmit through the bee population when honey bee colonies cast reproductive swarms, phoretic mites travel upon the swarming bees to the new nest site, worker bees shift into another colonies, and when foraging $(V$. destructor can move from flowers onto foraging bees), as well as when beekeepers move bees or infested brood between hives (Peck et al. 2016). However, honey bees' behaviour traits that might limit the growth of the Varroa mite population are high swarming (Fries et al. 2006), absconding tendencies, hygienic behaviour (social trait of removing dead and infected pupae) and grooming behaviour (Kurze et al. 2016; Nganso et al. 2017). Additionally, physiological trait makes honey bees resistant to Varroa by reducing the mite reproductive success. These traits enable African 
honey bees to co-exist with $V$. destructor (Strauss et al. 2016; Nganso et al. 2018; Gebremedhn et al. 2019).

The severity of $V$. destructor infestation and its impact differs among different honey bee populations and among managed, feral and wild populations. The pest is regarded as highly destructive and has caused periodic losses of bee colonies in the USA and Europe and less devastation in African honey bees (Rosenkranz et al. 2010). The behaviour of $V$. destructor varies with places: in some places, the infestation levels of mites were found to be lower in native as compared to exotic honey bees (Alattal et al. 2017), while in other places the infestation between wild and managed colonies were relatively similar across different agro-ecological zones, with spreading observed from lower to higher elevations (Chemurot et al. 2016).

$V$. destructor is known to be influenced by bioclimatic conditions in terms of occurrence and distribution. This suggests that climate can have an important role in the host-parasite interaction (Muli et al. 2014) and that the mite can survive and flourish in certain optimal bioclimatic conditions. However, specificity for the optimal temperature, humidity, and precipitation may differ among subspecies of honey bee and their pests (Peterson and Nakazawa 2008). Study has shown that the reproductive ability of other honey bee pests can be enhanced by hot and humid conditions (Fazier et al. 2010). Thus, changes in optimal bioclimatic conditions may be a stressor for the honey bees, leading to increased vulnerability to parasites (Goulson et al. 2015). On the verge of increased climate change complexities, some patterns of the honey bees and their parasitic mite are expected to be influenced.

Climate change has manifested itself in various forms that affect human livelihoods and landscapes at different scales. Global efforts are geared to restrict further deterioration of climate by containing temperature rise below $2{ }^{\circ} \mathrm{C}$ by the end of the century to avoid catastrophic outcomes (Parry et al. 2007; Kiatoko et al. 2014). Transformations of the habitats due to climate change have altered the ecological niches of various species of flora and fauna through disruptions of ecological processes (Mooney et al. 2009). For instance, geographical ranges of forest ecosystems are expected to shift upwards along the elevations and suitability areas for some species have either expanded or shrank, depending on their optimal operating conditions (Melles et al. 2011). Pests and diseases have been reported to increase due to impacts of climate change to the areas where they never had been previously reported (Kovats et al. 2001; Anderson et al. 2004). In the long run, the manifestation of the effects of pests and diseases to the host population becomes severe and detrimental (Le Conte and Navajas 2008; Chakraborty and Newton 2011). In pursuit to improve general understanding and prepare for the control of $V$. destructor in light of climate change, there is need to predict future threats through identification of suitable locations that will act as future niches for the mite. It is therefore, important to employ niche modelling to gain a better understanding of the future spread of $V$. destructor in Tanzania.

There are varieties of species distribution modelling methods available for prediction of potential suitable habitats for a species (Elith et al. 2006). Generalized regressions, Bayesian approach, neural networks, classification techniques, and environmental envelopes are among the broad groups of methods developed over the years (Phillips et al. 2006). Some of these methods are based on presence-only data while majority of them are based on presence/absence data. Classification and regression tree analysis, artificial neural networks (ANN), generalized linear models (GLM) and generalized additive models (GAM) require presence/absence data (Elith et al. 2006). Presence-only methods include bioclimatic envelope algorithm BIOCLIM, DOMAIN and MaxEnt (Phillips and Dudík 2008). Presence-only methods rely on the establishment of environmental envelopes around locations where species occur, which are then compared to the environmental conditions of background areas (Thuiller et al. 2004). Maximum entropy (MaxEnt) modelling (Phillips et al. 2006) in particular has been widely used and shown promising results (Elith et al. 2006) and performs better than many different modelling methods in model comparisons when presence-only data are used (Ortega-Huerta and Peterson 2008).

MaxEnt models have proved to be useful for documenting and understanding the effects of climate change on distribution of both flora and fauna (Urbani et al. 2017; Zhang et al. 2018). The MaxEnt modelling approaches have been widely used to provide a link between the spatial variations in the bioclimatic variables and the distribution of species due to their preferences (Phillips et al. 2006). It derives the probability distribution of species based on georeferenced presence records and environmental variables (Phillips et al. 2006). MaxEnt is a general-goal-oriented machine learning method that utilizes presence-only data (Phillips et al. 2006). The maximum entropy models formed based on the fact that when characterizing some unknown events with a statistical model, the one presenting maximum entropy should always be chosen as it produces the uniform distribution while accurately infers the observed data (Dudik et al. 2004). It has advantages over other species distribution modelling as it requires species presenceonly data, and both categorical and continuous variables can be used (Dudik et al. 2004; Phillips and Dudík 2008). Several studies have demonstrated MaxEnt's ability to accurately predict species distribution in a wide range of 
ecological and geographical regions (Thuiller et al. 2005; Yi et al. 2018; Mwakapeje et al. 2019). Subsequently, conservation practitioners have been increasingly using habitat suitability models from MaxEnt to make management decisions (Loiselle et al. 2003; Saatchi et al. 2008).

The parasite mite ( $V$. destructor) is widespread in Tanzania, throughout the western, central and northeastern parts of the country. Previous studies have identified presence of $V$. destructor in various parts of Tanzania (Fazier et al. 2010; Mumbi et al. 2014). Additionally, some opportunistic observations have later identified presence of $V$. destructor in areas that were previously not reported (Bee Observer 2018). The likelihood that $V$. destructor might be present in some other parts of the country that was previously unknown cannot be ruled out. The aim of this study was therefore to assess potential risk areas for infestation of $V$. destructor by modelling its current and future distributions in Tanzania under two IPCC Representative Concentration Pathway (rcp) scenarios. The fact that $V$. destructor is present in some localities and not others implies that there are suitable areas where it flourishes while in others it does not; hence, its spread is not merely due to hosts presence but also the conditions that favours its overall environmental suitability. We projected the potential distributions for $V$. destructor in 2055 and 2085 under two climate scenarios (rcp4.5 and rcp8.5). These results are important to identify potential future suitable climate space for $V$. destructor in Tanzania to inform conservation priorities for interventions of this most devastating pest to honey bees. It is also important to provide information for improving surveillance planning aimed at improved honey bee production that is considered as an economic and forest conservation activity in Tanzania.

\section{Materials and methods}

Study area

The United Republic of Tanzania is located in East Africa between longitude $29^{\circ}$ and $41^{\circ}$ East and latitude $1^{\circ}$ and $12^{\circ}$ South (Fig. 1). Tanzania is endowed with a wide range of natural resources as well as ecological and cultural diversity including extensive areas of arable land,

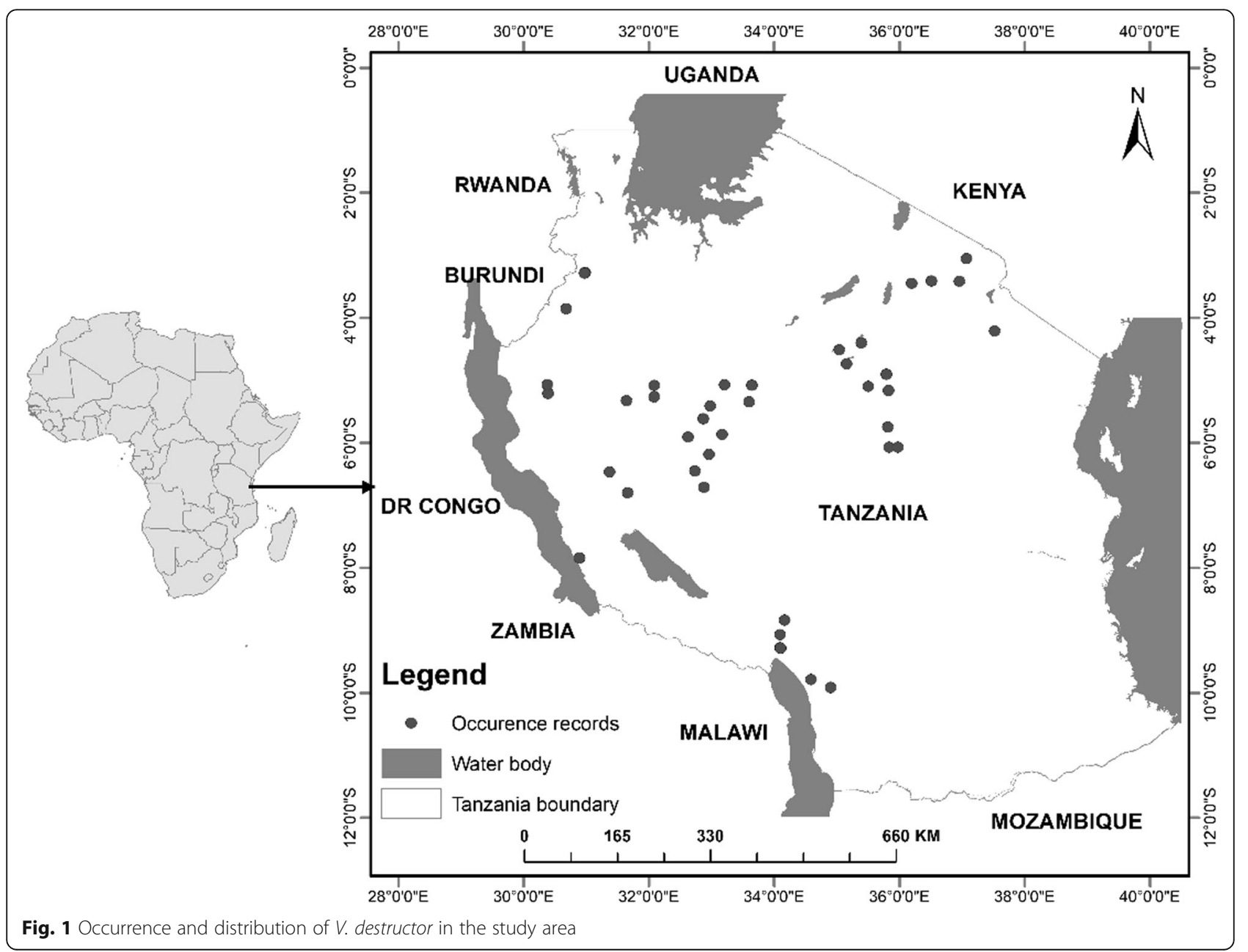


wildlife reserves and parks, mountains, forest reserves, rivers and lakes. The mean annual rainfall varies from below 500 to over $2000 \mathrm{~mm}$ per annum while the mean temperature ranges from -4.9 to $27.9{ }^{\circ} \mathrm{C}$ per annum. The central and western plateau is relatively dry while the northern and southern highlands are cool. Rainfall for large parts of the country is bimodal with short rains from October-December and long rains from March to May (Magehema et al. 2014) .

\section{Methods}

Sampling for this study took into consideration areas with high potentials for beekeeping activities, altitudinal zonation (highlands vs. lowlands) and different agroecological zones of Tanzania. It involved sampling in the forests and farmlands. Purposive sampling was applied to select 25 districts across the country for the survey. Presence of $V$. destructor was determined through careful observations within the hives: on the body of bees, on the combs surface, combs cells and hive walls. Further examination of the mites was done with the extraction using the powdered sugar roll sampling method. Selected brood combs were carefully picked, and bees were put into bucket using a bee brush. About 100 to 200 bees were put into wide mouth glass jar and covered with wire mesh. Two tablespoons of powdered sugar were administered into the jar. The jar was stirred-up by rolling sideways after every 2 min to allow even distribution of sugar over the bees. After 5 min, sugar and mites were poured from the jar into a white cloth and then sieved to remain with only mites on cloth surface. A counting of mites was conducted, and the bees were returned to the hive (Mumbi et al. 2014).

Overall, a total of 175 honey bee colonies were inspected and 84 (48\%) were found to be infected by $V$. destructor. Presence data for $V$. destructor were recorded with geospatial data, and severity of the infestation was noted as per standard methods (Dietemann et al. 2013). The presence records (84) were within the sample sizes acceptable in MaxEnt modelling environment (Haredasht et al. 2013); subsequently, these presence records were used for modelling potential current and future risk distribution in Tanzania under climate change.

A total of 19 bioclimatic datasets were obtained from KITE database and used in the study. All bioclimatic layers had 1-km resolution. Before modelling, we applied autocorrelation to test for collinearity between variables at each level, to eliminate highly auto-correlated variables while avoiding model overfitting (Chala et al. 2016). For instance, a pair of variables found to have a correlation coefficient $\geq 7$; one of the variables was removed from the analysis. Test model runs identified seven out of the 19 variables as most uncorrelated with the current distributions: annual mean temperature (bio1), mean diurnal range (bio2), isothermality (bio3), annual precipitation (bio12), rainfall of driest month (bio14), potential evaporation (Pet) and number of dry months (Dm).

We used $75 \%$ of occurrence records to build the model and the remaining $25 \%$ for model validation (Mweya et al. 2016). The importance and contribution of the climatic variables was determined using the Jackknife method (Phillips and Dudík 2008). The model's accuracy was examined based on the area under the curve (AUC) of the receiver operating characteristic (ROC) plot (Phillips and Dudík 2008). The higher values were obtained for AUC (0.85), indicating that there is a higher than random chances when a randomly picked presence site would contain a higher predictive value than a randomly selected background site implying more discriminative power between presence $v s$. absence (Elith et al. 2006). In the assessment of the impact of climate change on the distribution of $V$. destructor, the future climate models for 2055 and 2085 were constructed based on high-resolution ensemble of climate projections for Africa (Platts et al. 2015). We considered two representative concentration pathways (RCPs), RCP 4.5 and RCP 8.5 , for a moderate and an extreme greenhouse gas emission scenario respectively in our modelling (van Vuuren et al. 2011). To identify highly suitable cells from unsuitable ones, we reclassified continuous MaxEnt model to categorical map based on the probability of presence threshold. We later estimated the area under infestation potential of $V$. destructor in Tanzania, through reclassified current and future risk maps from risk categories of all regions of Tanzania.

\section{Results}

Climate variables affecting $V$. destructor distribution

The model for current and future suitability distribution for $V$. destructor provided excellent results, with a testing and training AUC values of $0.87 \pm 0.03$ and $0.85 \pm$ 0.03 , respectively, which is greater than 0.5 of a random model (Phillips et al. 2006). This implies that the climatic predictors used for the suitability analysis leads to the excellent prediction result (Lawler et al. 2006). The combination of mean diurnal range in temperature, mean temperature, and mean annual rainfall were the top three climatic variables that accounted for $76.2 \%$ of the distribution modelling $V$. destructor (Table 1).

The mean diurnal range of temperature was found to be the most influential factor, as it indicated highest gain when used in isolation (Fig. 2).

Areas with mean diurnal range in temperature ranging from 11.5 to $14.5{ }^{\circ} \mathrm{C}$ were found to be suitable for $V$. destructor. Overall, the annual mean temperature and annual mean rainfall were noted to be important, with suitability ranging from 0 to $20{ }^{\circ} \mathrm{C}$ and from 1600 to $2800 \mathrm{~mm}$ for temperature and rainfall respectively. 
Table 1 Variable contributions in the potential distribution of $V$. destructor in Tanzania

\begin{tabular}{lll}
\hline Variables & Abbreviation & $\begin{array}{l}\text { Percent contribution } \\
(\%)\end{array}$ \\
\hline $\begin{array}{l}\text { Mean diurnal range in } \\
\text { temperature }\end{array}$ & bio2 & 43.9 \\
Annual mean temperature & bio1 & 20.6 \\
Annual mean rainfall & bio12 & 11.7 \\
Isothermality & bio3 & 8.9 \\
Rainfall driest month & bio14 & 7.5 \\
Potential evaporation & Pet & 7.3 \\
Number of dry months & Dm & 0.2 \\
\hline
\end{tabular}

\section{Predicted distribution risk areas of $\mathrm{V}$. destructor}

Predicted distributions under current conditions revealed that highly and moderately suitable areas for $V$. destructor were found to be mainly distributed in the Western, Southern Highlands and Central zones with larger magnitude being recorded in Tabora, Mbeya and Dodoma regions respectively (Fig. 3a). Marginally areas concentrated in the Central, Lake and Northern zones while unsuitable areas were largely found in the Eastern and Lake zones and small magnitude in some regions of Western zone (i.e. Kagera), Southern Highland (i.e. Iringa) and Northern zone (i.e. Arusha) (Fig. 3a).

According to future predictions (Fig. 3b-e), the highly suitable area for $V$. destructor in Western and Southern Highland zones showed the most obvious decline, with very small highly suitable areas remaining in Iringa region although marginally suitable areas increased under future mid-century climate conditions for both scenarios rcp45 and rcp85 compared to current conditions (Fig. 4). Even though highly suitable areas declined for the two zones at the mid of century, the class of highly suitable areas significantly increased at the end of century for both scenarios rcp45 and rcp85 compared to mid-century scenarios (Fig. 4). Generally, Western, Southern and Central zones remained the leading zones with extensive highly and moderately suitable areas between mid-century and late-century for both scenarios rcp45 and rcp85. The leading zone with marginally suitable areas was central zone throughout the two periods for both scenarios.

In the mid-century 2055, the Western zone remained the leading area with highly suitable conditions for both scenarios rcp4.5 and 8.5 (Fig. 4). At the end of century
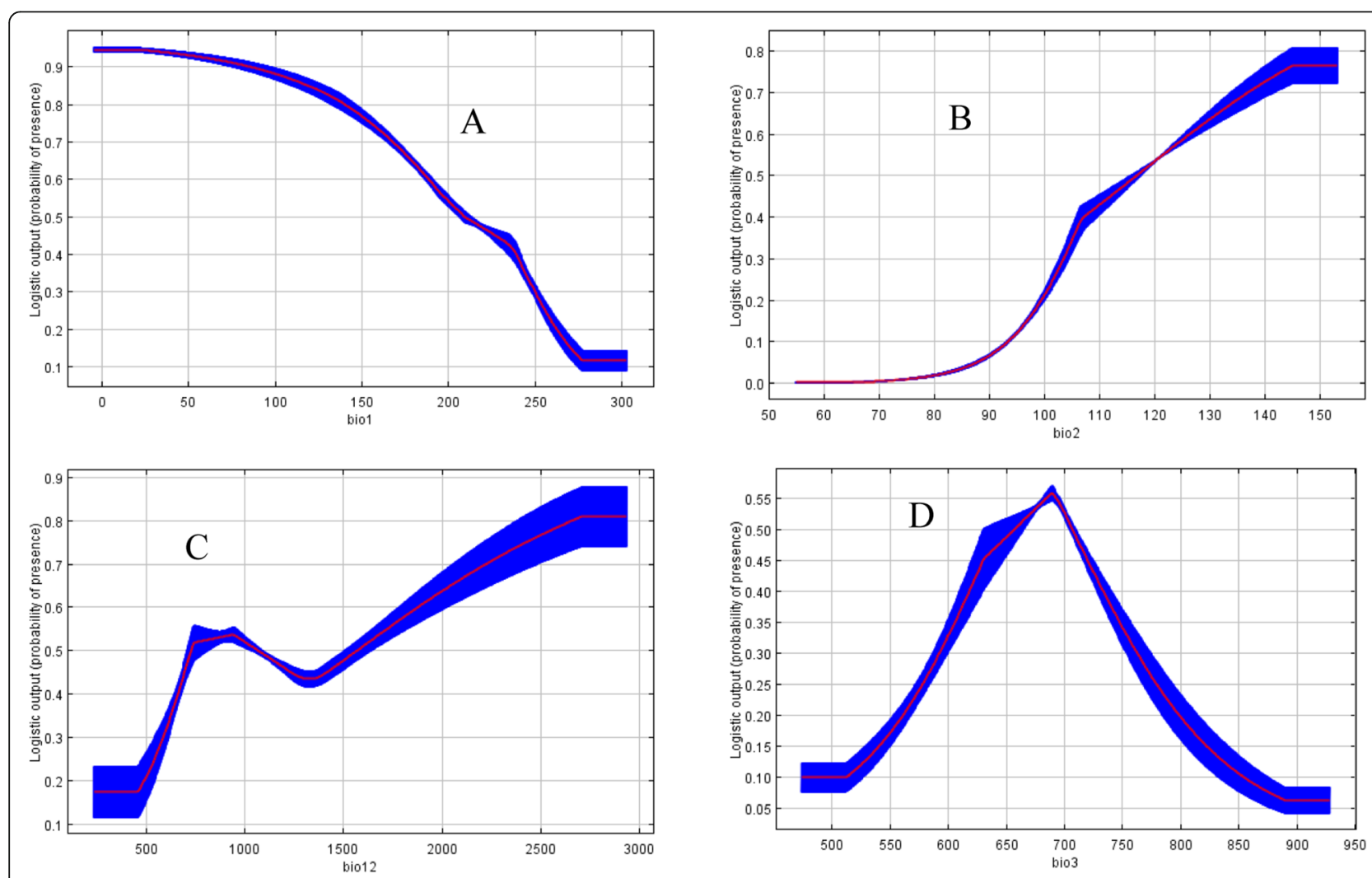

Fig. 2 Response of $V$. destructor to environmental variables. a Mean diurnal range in temperature (factor 10). $\mathbf{b}$ annual mean temperature (factor 10). c Annual mean rainfall. $\mathbf{d}$ Isothermality (times 10) 


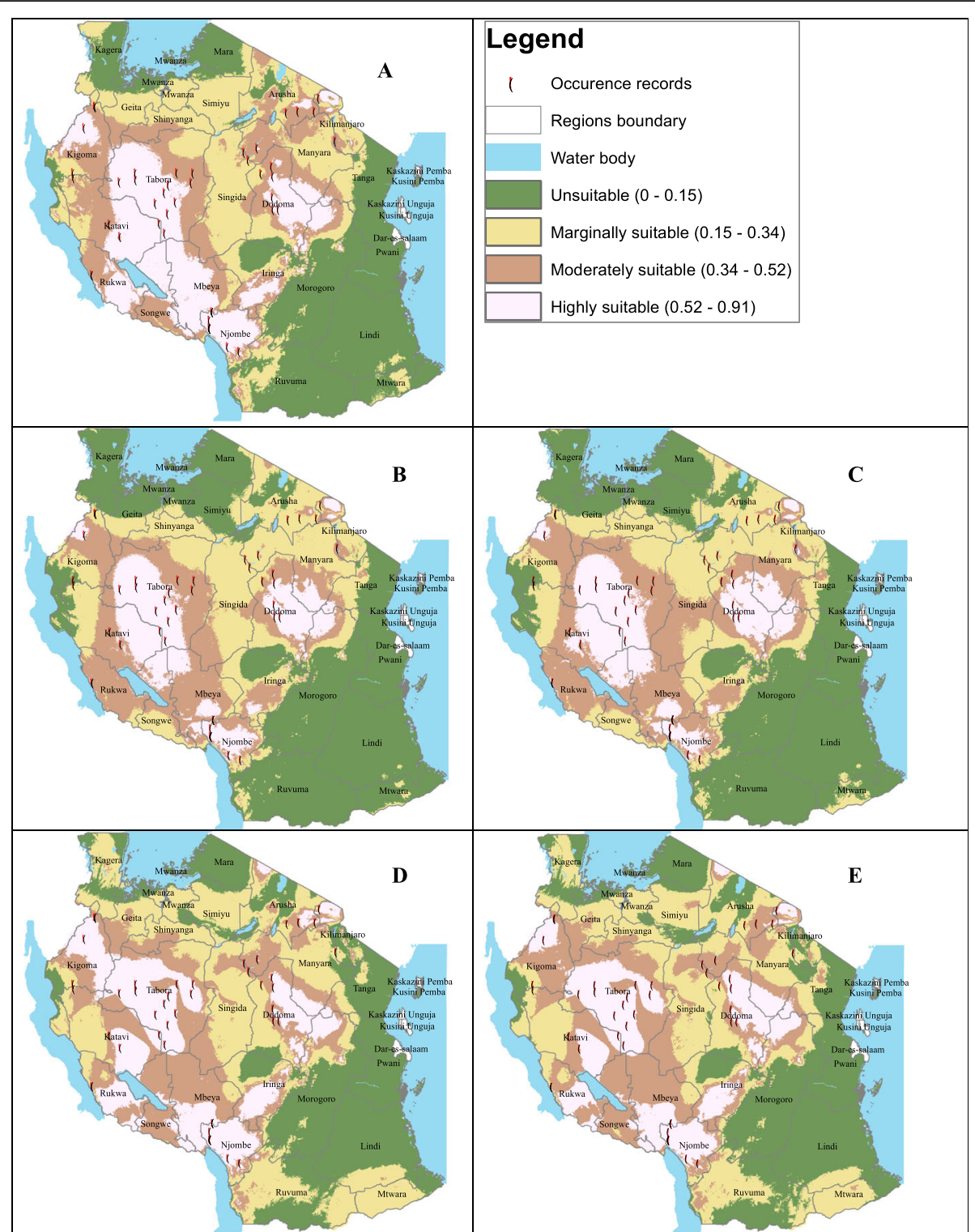

Fig. 3 Potential suitability areas for V. destructor in Tanzania. a Current scenario. b Mid-century rcp4.5 scenario. c Mid-century rcp8.5 scenario. d Late-century rcp 4.5 scenario. e Late-century rcp8.5 scenario

2085, the Southern Highlands and Western zones were found to contain more areas with highly suitable conditions for scenarios rcp4.5 and 8.5.

Overall, there is consistent net decrease of highly suitable areas for $V$. destructor habitation throughout the country in future projections in mid- and late-century for both rcp4.5 and 8.5 (Fig. 5). Marginally suitable areas will have net increase in late-century 2085 and net decrease at mid-century in 2055 under both rcp4.5 and 8.5.

\section{Discussion}

Climate variables were found to influence the prediction model that described the suitability of $V$. destructor in different agro-ecological zones of Tanzania. While combination of variables (mean diurnal temperature, annual mean temperature and annual mean rainfall) has exerted greater influence of over $76 \%$, yet in isolation, each of the key parameters had significant influence in the model. Variables describing temperature (mean diurnal range in temperature and annual mean temperature) were the most important contributors to MaxEnt models. This suggests that temperature can have an important role in the host-parasite interaction and may influence the mite infestation rates. Our current study and many others have indicated that $V$. destructor flourish at temperature range between 22 and $33.4{ }^{\circ} \mathrm{C}$ (Le Conte and Navajas 2008; Muli et al. 2014; Rosenkranz et al. 2010; Pätzold and Ritter 1989). This provides the mites 


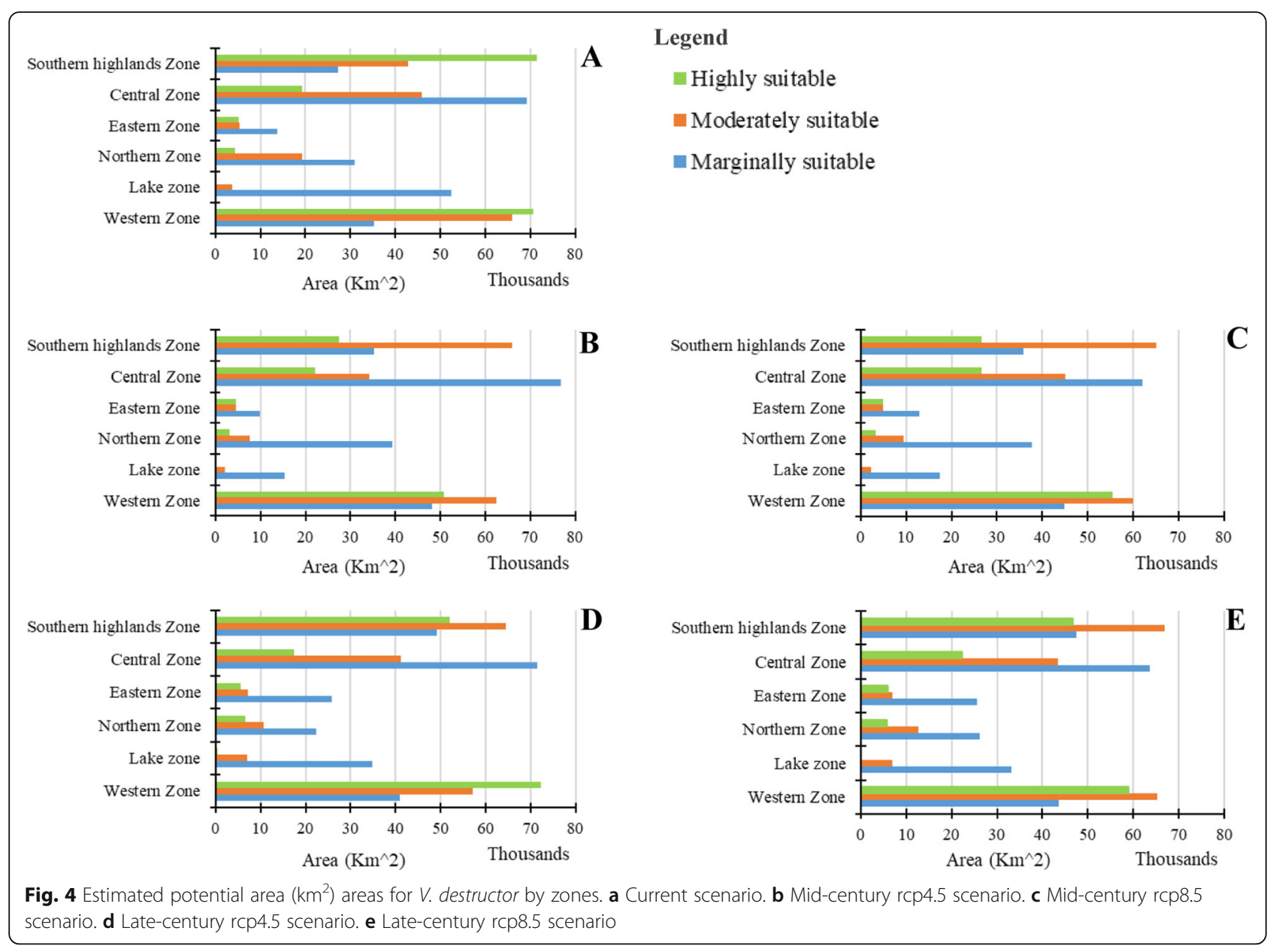

with wide range of suitable temperature to spread and cause infestation especially in Tanzania which provide such favourable climatic conditions.

In the bioclimatic cluster, precipitation variables (annual mean rainfall and rainfall driest month) demonstrated relatively higher contribution to the models and hence influence the spread of $V$. destructor. Changing patterns of precipitation which is predicted in various parts of Tanzania will have direct influence to the expansion of the highly and moderate suitable areas that will accommodate $V$. destructor. Overall, our study demonstrated that climate variables have highest contribution in predicting the sensitivity of $V$. destructor and may therefore influence their distribution patterns in Tanzania. Similarly, Makori et al. (2017) reported similar observations that include rainfall variables which had the highest relative contribution in predicting spatial distribution of honey bees' pests.

Our results noted that the Western zone of Tanzania is consistently possessing highly suitable areas at the present, mid- and late-century for $V$. destructor's host under both climate scenarios of rcp4.5 and 8.5. This implies that under all circumstances, $V$. destructor will maintain their presence in the western zone and it is where research and management interventions will need to be applied to inform better ways to contain the spread of the mites. The Eastern, Northern and Lake zones of Tanzania have recorded limited spread of $V$. destructor which may imply the absence of favourable conditions for it to flourish in the present time and in future projections both at midand late-century for rcp4.5 and 8.5. Available records do not indicate observations of $V$. destructor in those areas, and this might be a limitation of data capture or may imply non-severity of the spread of the mite. This calls for further investigation of the presence of mites in the Eastern, Northern and Lake zones at more detailed scale in order to ascertain our initial observations for better management of beekeeping enterprises.

Suitability of $V$. destructor in mid- and late-century under both rcp4.5 and 8.5 indicates a general decline of highly suitable areas in terms of coverage. This is good sign in one aspect indicating that climate change will limit the spread of the mite by reducing extent of highly favourable conditions for it to flourish. However, this shrinking may lead to high concentration of $V$. destructor infestation in fewer hotspots. Surprisingly, the further 


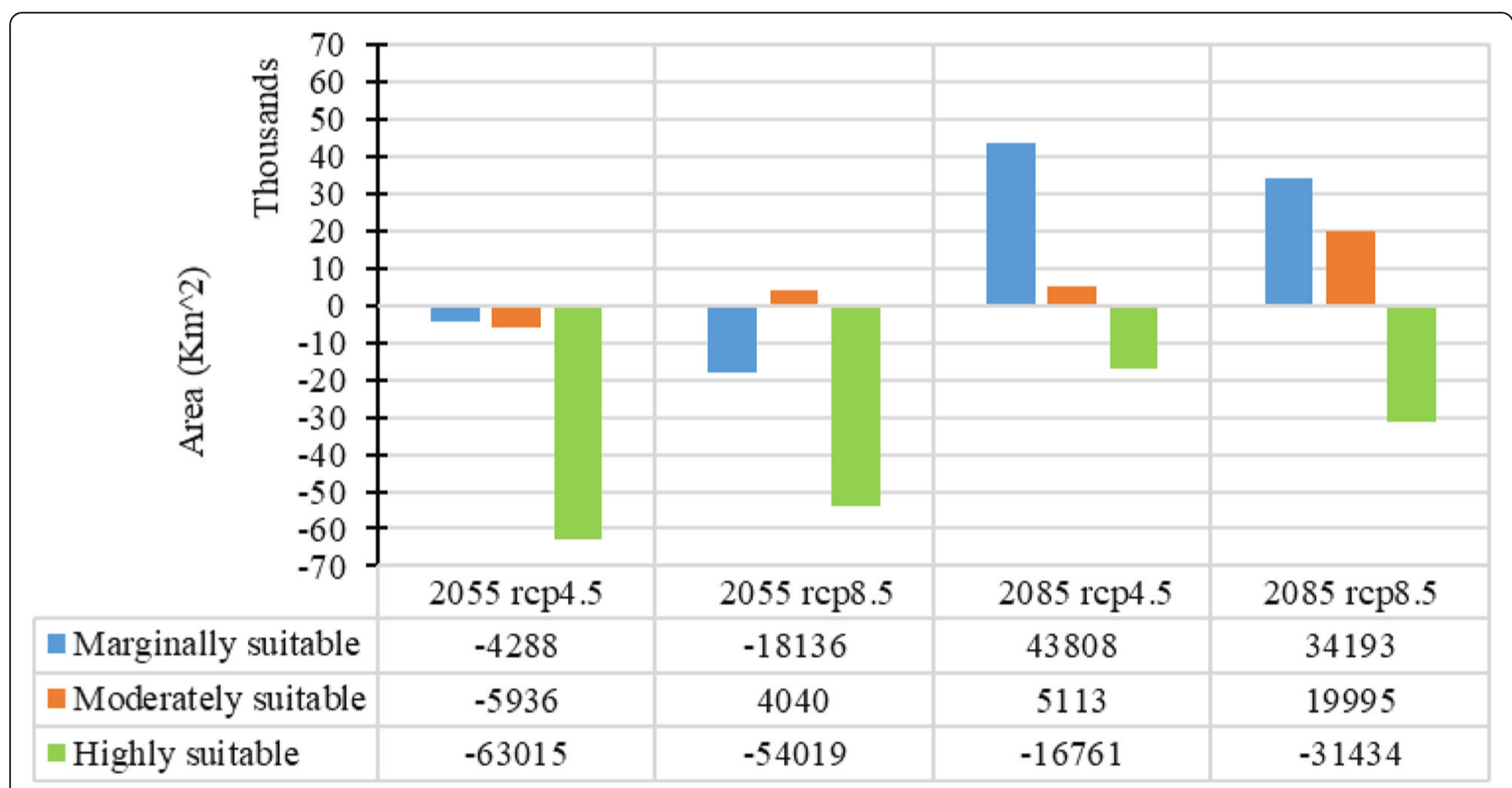

Fig. 5 Estimated potential area $\left(\mathrm{km}^{2}\right)$ increase or decrease (-) from current potential distribution for $V$. destructor in Tanzania

spread of $V$. destructor due is projected to occur in moderately and marginally suitable areas especially in latecentury under both climate scenarios of rcp4.5 and 8.5. This is a negative development as possibility of entry into new areas still exists. It is unknown at this stage as to whether the moderately and marginally suitable areas will over time transform to be the highly favourable for the mites to flourish further. This is very risk scenario as the spread of mites is of much concern even when we foresee a limited incursion to new areas.

The existing strategies and plans to foster beekeeping development in Tanzania lack adequate information on steps to address challenges of bees' pests and diseases such as $V$. destructor (URT 2018). Research to understand the traits other than influence of climate conditions needs to be unveiled to provide insights for possible interventions to address the risks of spread. The recent efforts by the government of Tanzania to revamp beekeeping research through institutional arrangements and capacity enhancement of the beekeeping laboratory in Arusha city is a good indication of the attached importance of the contribution of the science to promote beekeeping. We anticipate that, given the risks provided by $V$. destructor in beekeeping industry, the beekeeping research program will make it one of the priority areas for interventions.

\section{Conclusions}

The current and predicted areas of habitat suitability for $V$. destructor provides information useful for beekeeping stakeholders in Tanzania to consider the impending risks and allow adequate interventions to address challenges facing honey bees and the beekeeping industry. The predicted shifts in Varroa pest distribution patterns at country level are useful in developing monitoring strategies to detect future infestations in currently uninfested regions. Therefore, in potentially suitable regions for future infestations, we recommend that special precautions should be taken to contain $V$. destructor and limit future spread. Research programs that focus on the use of integrated pest management should be developed and implemented in order to limit the spread of $V$. destructor.

\section{Abbreviations}

ANN: Artificial neural networks; AUC: Area under the curve; FAO: Food and Agriculture Organization; GAM: Generalized additive models;

GLM: Generalized linear models; IPCC: Intergovernmental Panel on Climate

Change; NGOs: Non-Governmental Organizations; RCP: Representative

concentration pathway; ROC: Receiver operating curve; URT: United Republic of Tanzania; USD: United States Dollar

\section{Acknowledgements}

The authors thank the reviewers for their helpful comments and improvements suggested. The authors acknowledge the climate data providers WorldClim and KITE resources and MAXENT authors for the Java software version of the model.

\section{Authors' contributions}

All authors collaborated in an equal manner in writing the manuscript. All authors read and approved the final manuscript.

\section{Authors' information}

No additional information

Funding

Nothing to inform 


\section{Availability of data and materials}

Nothing to inform

\section{Ethics approval and consent to participate}

No ethics or conflict of interest exists.

\section{Consent for publication}

The authors consent to publish the information included in this draft

\section{Competing interests}

The authors declare that they have no competing interests.

\begin{abstract}
Author details
${ }^{1}$ School of Life Sciences and Bio-Engineering, The Nelson Mandela African Institution of Science and Technology, P.O. Box 447, Arusha, Tanzania. ${ }^{2}$ Beekeeping Training Institute, P.O. Box 62, Tabora, Tanzania. ${ }^{3}$ Centre for Ecological and Evolutionary Synthesis (CEES), Department of Biosciences, University of Oslo, Oslo, Norway. ${ }^{4}$ Dar es Salaam, Tanzania.
\end{abstract}

\section{Received: 9 March 2020 Accepted: 4 August 2020}

Published online: 17 September 2020

\section{References}

Al Ghamdi A, Hoopingarner R (2004) Modeling of honey bee and varroa mite population dynamics. Saudi J Biol Sci 11:21-36

Alattal Y, AlGhamdi A, Single A et al (2017) Fertility and reproductive rate of Varroa mite, Varroa destructor, in native and exotic honeybee, Apis mellifera L. , colonies under Saudi Arabia conditions. Saudi J Biol Sci 24:992-995 https:// doi.org/10.1016/j.sjbs.2016.12.018

Anderson PK, Cunningham AA, Patel NG et al (2004) Emerging infectious diseases of plants: Pathogen pollution, climate change and agrotechnology drivers. Trends Ecol Evol 19:535-544 https://doi.org/10.1016/j.tree.2004.07.021

Bee Observer (2018) A note on the occurrence of Varroa destructor in Singida, Tanzania. https://www.beeobserver.org/varroa-in-africa. Accessed 20 Mar 2020

Boecking O, Genersch E (2008) Varroosis - the ongoing crisis in bee keeping. J Consum Prot Food S 3:221-228 https://doi.org/10.1007/s00003-008-0331-y

Chakraborty S, Newton AC (2011) Climate change, plant diseases and food security: an overview. Plant Pathol 60:2-14 https://doi.org/10.1111/j.13653059.2010.02411.x

Chala D, Brochmann C, Psomas A et al (2016) Good-bye to tropical alpine plant giants under warmer climates? Loss of range and genetic diversity in Lobelia rhynchopetalum. Ecol Evol 6:8931-8941 https://doi.org/10.1002/ece3.2603

Chemurot M, Akol AM, Masembe C et al (2016) Factors influencing the prevalence and infestation levels of Varroa destructor in honeybee colonies in two highland agro-ecological zones of Uganda. Exp Appl Acarol 68:497508 https://doi.org/10.1007/s10493-016-0013-x

Dietemann V, Nazzi F, Martin SJ et al (2013) Standard methods for varroa research. J Apic Res 52:52.1.09 https://doi.org/10.3896/IBRA.1.52.1.09

Donzé G, Guerin PM (1994) Behavioral attributes and parental care of Varroa mites parasitizing honeybee brood. Behav Ecol Sociobiol 34:305-319 https:// doi.org/10.1007/BF00197001

Dudik M, Phillips SJ, Schapire RE (2004) Performance guarantees for regularized maximum entropy density estimation. Lect Notes Artif Intell (Subseries Lect Notes Comput Sci) 3120:472-486 https://doi.org/10.1007/978-3-540-27819-1_ 33

Elith JH, Graham CP, Anderson R et al (2006) Novel methods improve prediction of species' distributions from occurrence data. Ecography (Cop) 29:129-151 https://doi.org/10.1111/j.2006.0906-7590.04596.x

Fazier M, Muli E, Conklin T et al (2010) A scientific note on Varroa destructor found in East Africa; Threat or opportunity? Apidologie 41:463-465 https:// doi.org/10.1051/apido/2009073

Fries I, Imdorf A, Rosenkranz P (2006) Survival of mite infested (Varroa destructor) honey bee (Apis mellifera) colonies in a Nordic climate. Apidologie 37:564570 https://doi.org/10.1051/apido:2006031

Gebremedhn H, Amssalu B, De Smet L, De Graaf DC (2019) Factors restraining the population growth of Varroa destructor in Ethiopian honey bees (Apis mellifera simensis). PLoS One 14:e0223236 https://doi.org/10.1371/journal. pone.0223236
Giacobino A, Molineri Al, Pacini A et al (2016) Varroa destructor and viruses association in honey bee colonies under different climatic conditions. Environ Microbiol Rep 8:407-412 https://doi.org/10.1111/1758-2229.12410

Goulson D, Nicholls E, Botías C, Rotheray EL (2015) Bee declines driven by combined stress from parasites, pesticides, and lack of flowers. Science 347: 1255957

Gracia MJ, Moreno C, Ferrer M et al (2017) Field efficacy of acaricides against Varroa destructor. PLoS One 12:e0171633 https://doi.org/10.1371/journal. pone.0171633

Haredasht SA, Barrios M, Farifteh J et al (2013) Ecological niche modelling of bank voles in Western Europe. Int J Environ Res Public Health 10:499-514 https://doi.org/10.3390/ijerph10020499

Huang Z (2014) Varroa mite reproductive biology. Life History of Varroa.:1-9

Kiatoko N, Raina SK, Muli E, Mueke J (2014) Enhancement of fruit quality in Capsicum annum through pollination by Hypotrigona gribodoi in Kakamega, Western Kenya. Entomol Sci 17:106-110 https://doi.org/10.1111/ens.12030

Kovats RS, Campbell-Lendrum DH, McMichael AJ et al (2001) Early effects of climate change: Do they include changes in vector-borne disease? Philos Trans R Soc B Biol Sci 356:1057-1068 https://doi.org/10.1098/rstb.2001.0894

Kurze C, Routtu J, Moritz RFA (2016) Parasite resistance and tolerance in honeybees at the individual and social level. Zoology 119:290-297 https:// doi.org/10.1016/j.zool.2016.03.007

Lawler JJ, White D, Neilson RP, Blaustein AR (2006) Predicting climate-induced range shifts: Model differences and model reliability. Glob Chang Biol 12: 1568-1584 https://doi.org/10.1111/j.1365-2486.2006.01191.x

Le Conte Y, Navajas M (2008) Climate change: impact on honey bee populations and diseases. Rev Sci Tech 27:499-510 https://doi.org/10.20506/rst.27.2.1819

Loiselle BA, Howell CA, Graham CH et al (2003) Avoiding pitfalls of using species distribution models in conservation planning. Conserv Biol 17:1591-1600 https://doi.org/10.1111/j.1523-1739.2003.00233.x

Magehema A, Chang L, Mkoma S (2014) Implication of rainfall variability on maize production in Morogoro. Tanzania. Int J Environ Sci 4:1077-1086 https://doi.org/10.6088/ijes.2014040404547

Makori DM, Fombong AT, Abdel-Rahman EM et al (2017) Predicting spatial distribution of key honeybee pests in Kenya using remotely sensed and bioclimatic variables: key honeybee pests distribution models. ISPRS Int J Geo-Inf 6:66 https://doi.org/10.3390/ijgi6030066

Melles SJ, Fortin MJ, Lindsay K, Badzinski D (2011) Expanding northward: Influence of climate change, forest connectivity, and population processes on a threatened species' range shift. Glob Chang Biol 17:17-31 https://doi. org/10.1111/j.1365-2486.2010.02214.x

Mooney H, Larigauderie A, Cesario M et al (2009) Biodiversity, climate change, and ecosystem services. Curr Opin Environ Sustain 1:46-54 https://doi.org/10. 1016/j.cosust.2009.07.006

Moore PA, Wilson ME, Skinner JA (2014) Honey bee viruses, the deadly Varroa mite associates. Department of Entomology and Plant Pathology, the University of Tenessee, Knoxville. https://bee-health.extension.org/honey-beeviruses-the-deadly-varroa-mite-associates/ (Accessed 30 May 2020).

Muli E, Patch H, Frazier M et al (2014) Evaluation of the distribution and impacts of parasites, pathogens, and pesticides on honey bee (Apis mellifera) populations in east Africa. PLoS One 9:e94459 https://doi.org/10.1371/journal. pone.0094459

Mumbi CT, Mwakatobe AR, Mpinga IH et al (2014) Parasitic mite, Varroa species (Parasitiformes: Varroidae) infesting the colonies of African honeybees, Apis mellifera scutellata (Hymenoptera: Apididae) in Tanzania. J Entomol Zool Stud 2:188-196

Mwakapeje ER, Ndimuligo SA, Mosomtai G et al (2019) Ecological niche modeling as a tool for prediction of the potential geographic distribution of Bacillus anthracis spores in Tanzania. Int J Infect Dis 79:142-151 https://doi. org/10.1016/j.jij.2018.11.367

Mweya CN, Kimera SI, Stanley G et al (2016) Climate change influences potential distribution of infected Aedes aegypti co-occurrence with dengue epidemics risk areas in Tanzania. PLoS One 11:e0162649 https://doi.org/10.1371/journal. pone.0162649

Nazzi F, Le Conte Y (2016) Ecology of Varroa destructor, the major ectoparasite of the Western honey bee, Apis mellifera. Annu Rev Entomol 61:417-432 https:// doi.org/10.1146/annurev-ento-010715-023731

Nganso BT, Fombong AT, Yusuf AA et al (2017) Hygienic and grooming behaviors in African and European honeybees - New damage categories in Varroa destructor. PLoS One 12:e0179329 https://doi.org/10.1371/journal. pone.0179329 
Nganso BT, Fombong AT, Yusuf AA et al (2018) Low fertility, fecundity and numbers of mated female offspring explain the lower reproductive success of the parasitic mite Varroa destructor in African honeybees. Parasitology 145: 1633-1639 https://doi.org/10.1017/S0031182018000616

Ortega-Huerta MA, Peterson AT (2008) Modeling ecological niches and predicting geographic distributions: a test of six presence-only methods. Rev Mex Biodivers 79:205-216

Parry M, Parry M, Canziani O, Palutikof J (2007) Climate change 2007-impacts, adaptation and vulnerability: Working group II contribution to the fourth assessment report of the IPCC

Pätzold S, Ritter W (1989) Studies on the behaviour of the honey-bee mite, Varroa jacobsoni O., in a temperature gradient. J Appl Entomol 107:46-51 https://doi.org/10.1111/j.1439-0418.1989.tb00226.x

Peck DT, Smith ML, Seeley TD (2016) Varroa destructor mites can nimbly climb from flowers onto foraging honey bees. PLoS One 11:e0167798 https://doi. org/10.1371/journal.pone.0167798

Peterson AT, Nakazawa Y (2008) Environmental data sets matter in ecological niche modelling: an example with Solenopsis invicta and Solenopsis richteri. Glob Ecol Biogeogr 17:135-144 https://doi.org/10.1111/j.1466-8238.2007.00347.x

Phillips SJ, Anderson RP, Schapire RS (2006) Maximum entropy modeling of species geographic distributions. Ecol Model 190:231-259 https://doi.org/10. 1016/j.ecolmodel.2005.03.026

Phillips SJ, Dudík M (2008) Modeling of species distributions with Maxent: new extensions and a comprehensive evaluation. Ecography 31:161-175 https:// doi.org/10.1111/j.0906-7590.2008.5203.x

Platts PJ, Omeny PA, Machart R (2015) Article :AFRICLIM: high-resolution climate projections for ecological applications in Africa. Afr J Ecol. https://doi.org/doi. org/10.1111/aje.12180

Rosenkranz P, Aumeier P, Ziegelmann B (2010) Biology and control of Varroa destructor. J Invertebr Pathol 103:S96-S119 https://doi.org/10.1016/j.jip.2009.07.016

Saatchi S, Buermann W, ter Steege $\mathrm{H}$ et al (2008) Modeling distribution of Amazonian tree species and diversity using remote sensing measurements. Remote Sens Environ 112:2000-2017 https://doi.org/10.1016/j.rse.2008.01.008

Strauss U, Dietemann V, Human $\mathrm{H}$ et al (2016) Resistance rather than tolerance explains survival of savannah honeybees (Apis mellifera scutellata) to infestation by the parasitic mite Varroa destructor. Parasitology 143:374-387 https://doi.org/10.1017/S0031182015001754

Thuiller W, Araújo MB, Hirzel AH, Brotons L (2004) Presence-absence versus presence-only modelling methods for predicting bird habitat suitability. Ecography 27:437-448

Thuiller W, Lavorel S, Araujo MB et al (2005) Climate change threats to plant diversity in Europe. Proc Natl Acad Sci USA 102:8245-8250

UN Environment (2016) Pollinators vital to our food supply under threat. http:// www.fao.org/news/story/en/item/384726/icode/. Accessed 30 May 2020

United Republic of Tanzania (2018) Commercial Beekeeping Strategy in Tanzania; 20182023. Tanzania Forest Services Agency. Ministry of Natural Resources and Tourism, p 44

Urbani F, D'Alessandro P, Biondi M (2017) Using maximum entropy modeling (MaxEnt) to predict future trends in the distribution of high altitude endemic insects in response to climate change. Bull Insectology 70:189-200

van Vuuren DP, Edmonds J, Kainuma $M$ et al (2011) The representative concentration pathways: an overview. Clim Change 109:5-31 https://doi.org/ 10.1007/s10584-011-0148-Z

Yi YJ, Zhou Y, Peng CY et al (2018) The influence of climate change on an endangered riparian plant species: the root of riparian Homonoia. Ecol Indic 92:40-50 https://doi.org/10.1016/j.ecolind.2017.05.004

Zhang K, Yao L, Meng J, Tao J (2018) Maxent modeling for predicting the potential geographical distribution of two peony species under climate change. Sci Total Environ 634:1326-1334 https:/doi.org/10.1016/j.scitotenv.2018.04.112

Zion Market Research (2019) Honey market by type (alfalfa honey, wildflower honey, buckwheat honey, acacia honey, clover honey, and others), by application (food \& beverage, personal care products, pharmaceuticals, and others), and by packaging (bottle, jar, tube, tub, and others): global industry perspective, comprehensive analysis, and forecast, 2018-2025. https://www globenewswire.com/news-release/2019/04/25/1809300/0/en/Global-HoneyMarket-Will-Reach-USD-10-336-Million-By-2025-Zion-Market-Research.html. Accessed 30 May 2020

\section{Publisher's Note}

Springer Nature remains neutral with regard to jurisdictional claims in published maps and institutional affiliations.

\section{Submit your manuscript to a SpringerOpen ${ }^{\circ}$ journal and benefit from:}

- Convenient online submission

- Rigorous peer review

- Open access: articles freely available online

- High visibility within the field

- Retaining the copyright to your article

Submit your next manuscript at $\boldsymbol{\nabla}$ springeropen.com 